\title{
Camponesas em lutas pelo fim da violência contra as mulheres e pela produção de outras formas de existência
}

\author{
Peasants in struggles to end violence against women and the production of \\ other forms of existence
}

\section{Campesinas en luchas por el fin de la violencia contra las mujeres y por la producción de otras formas de existencia}

\section{Giovana Ilka Jacinto Salvaro}

${ }^{a}$ Professora no Programa de Pós-Graduação em Desenvolvimento Socioeconômico (PPGDS) e no Programa de Pós-Graduação em
Direito da Universidade do Extremo Sul Catarinense (UNESC), Criciúma, SC, Brasil - E-mail: giovanailka@gmail.com

Resumo: O presente trabalho apresenta reflexões iniciais sobre a emergência de lutas pelo fim da violência contra as mulheres, empreendidas pelo Movimento de Mulheres Camponesas do Brasil (MMC Brasil). Em uma rede ampla e complexa, o MMC emerge como um movimento social rural nacional constituído no ano de 2004 pela unificação de movimentos rurais autônomos de mulheres, com demandas e reivindicações por reconhecimento profissional, igualdade de gênero, defesa da vida, garantia e direitos, entre outras. A partir do diálogo com estudos realizados sobre movimentos rurais autônomos de mulheres e o MMC em diferentes regiões do Brasil, da análise de publicações e de discussões relacionadas ao $1^{\circ}$ Encontro Nacional do Movimento de Mulheres Camponesas, realizado no ano de 2013, é possível observar que as demandas expressas e que mobilizam ações de enfrentamento envolvem situações de violência sofridas por mulheres rurais no contexto doméstico, assim como denunciam desigualdades de gênero que regulam/controlam existências individuais e coletivas nas esferas privada e pública.

Palavras-chave: MMC. Violência contra as mulheres; Lutas de gênero.

Abstract: This paper presents initial reflections on the emergence of struggle to end violence against women, undertaken by the Movement of Peasant Women of Brazil (Brazil MMC). In a large and complex network, MMC emerges as a national rural social movement constituted in 2004 by the unification of autonomous rural women's movements, with demands for professional recognition, gender equality, the defense of life, guarantee of rights, among others. From the dialogue with studies on autonomous rural women's movement and the MMC in different regions of Brazil, the analysis of publications and related discussions from the First National Meeting of the Movement of Peasant Women, held in 2013, it is possible to observe that the demands expressed and that mobilize coping actions involve situations of violence suffered by women in the domestic context, as well as denouncing gender inequalities that regulate/control individual and collective existences in the private and public spheres.

Keywords: MMC. Violence against women. Gender struggles.

(cc) EY Direito autoral e licença de uso: Este artigo está licenciado sob uma Licença Creative Commons. Com essa licença você pode compartilhar, adaptar, para qualquer fim, desde que atribua a autoria da obra, forneça um link para a licença, e indicar se foram feitas alterações. 
Resumen: El presente trabajo presenta reflexiones iniciales sobre la emergencia de las luchas por el fin de la violencia contra las mujeres, emprendidas por el Movimiento de Mujeres Campesinas de Brasil (MMC Brasil). En una red amplia y compleja, el MMC emerge como un movimiento social rural nacional constituido en el año 2004 por la unificación de movimientos rurales autónomos de mujeres, con demandas y reivindicaciones por reconocimiento profesional, igualdad de género, defensa de la vida, garantía de derechos, entre otras. A partir del diálogo con estudios realizados sobre movimientos rurales autónomos de mujeres y el MMC en diferentes regiones de Brasil, del análisis de publicaciones y de discusiones relacionadas al Primero Encuentro Nacional del Movimiento de Mujeres Campesinas, realizado en el año 2013, es posible observar que las demandas expresas y que movilizan acciones de enfrentamiento involucran situaciones de violencia sufridas por mujeres rurales en el contexto doméstico, así como denuncian desigualdades de género que regulan/controlan existencias individuales y colectivas en las esferas privada y pública..

Palabras clave: MMC. Violencia contra las mujeres. Luchas de género.

\section{Como citar o artigo:}

SALVARO, Giovana Ilka Jacinto. Camponesas em lutas pelo fim da violência contra as mulheres e pela produção de outras formas de existência. Revista de Ciências Humanas, Florianópolis, v.52, 2018. DOI: 10.5007/21784582.2018.57262

\section{INTRODUÇÃO}

A emergência de lutas pelo fim da violência contra as mulheres, empreendidas pelo Movimento de Mulheres Camponesas do Brasil (MMC Brasil), apresenta-se como temática que instiga reflexões e a escrita deste artigo. O interesse por bandeiras de luta do MMC remonta ao ano de 2006, quando iniciei uma pesquisa de doutoramento sobre a constituição de sujeitos e subjetividades em lutas de gênero enquanto práticas do Movimento de Mulheres Camponesas em Santa Catarina (MMC/SC). Todavia, no que se refere às lutas pelo fim da violência contra as mulheres, trata-se ainda de uma aproximação inicial e de uma reflexão preliminar que se pretende ampliar com uma pesquisa de maior fôlego. No contexto brasileiro, como um movimento social nacional rural de mulheres, o Movimento de Mulheres Camponesas do Brasil foi constituído no ano de 2004 pela unificação de diferentes movimentos rurais autônomos de mulheres1 com trajetórias iniciadas na década de 1980 em diferentes regiões do país (SALVARO, 2010).

No que se refere aos processos de organização coletiva e encaminhamento das lutas, o MMC pode ser denominado como um novo movimento social (NMS), uma vez que visibiliza e traz para o foco demandas que envolvem a busca por mudanças em relações sociais cotidianas. Nos novos movimentos sociais, conforme ressalta Scherer-Warren (1996, p. 68), “o que há de inovador é a luta pela ampliação do espaço da cidadania, incluindo-se aí a busca de modificações das relações sociais cotidianas". Como novas formas de organizações camponesas, Scherer-Warren faz referência ao Movimento das Barragens (MAB), ao Movimento dos Sem-Terra (MST) e ao Movimento de Mulheres Agricultoras (MMA).

\footnotetext{
${ }^{1}$ Maria Ignez Paulilo (2004, p. 239) observa que "são chamados de movimentos autônomos de mulheres porque não recebem apoio financeiro estável de nenhuma instituição ou outro movimento".
} 
Segundo Gohn (2011, p. 336), como forças sociais organizadas, os movimentos sociais aglutinam pessoas em campos de atividades e experimentação social, as quais são geradoras de criatividade e inovações socioculturais: “a experiência da qual são portadores não advém de forças congeladas do passado - embora este tenha importância crucial ao criar uma memória que, quando resgatada, dá sentido às lutas do presente. A experiência recria-se cotidianamente, na adversidade das situações que enfrentam".

Os movimentos sociais rurais autônomos de mulheres, que integraram o movimento nacional e constituíram o MMC Brasil, assumiram a identidade política "mulheres camponesas", mantendo suas organizações estaduais e locais. Cabe destacar que até o ano de 2013, o referido movimento nacional estava organizado em 20 estados (MMC BRASIL, 2013a). Para a realização das atividades, além de uma estrutura de apoio, formada pelo escritório nacional, localizado em Brasília/DF, e a Secretaria Nacional, com sede em Passo Fundo/RS, o MMC está organizado em "Grupo de Base, Direções Municipais, Direções Regionais, Direções Estaduais, Coordenação Nacional, Direção Executiva” (MMC BRASIL, 2013a).

Quanto à identidade política denominada mulheres camponesas, "ao que parece, a utilização da categoria camponesa não deve ser tomada como uma simples substituição de termos, na medida em que essa mudança conceitual (e política), em um mesmo gesto, amplia e unifica movimentos na e pela criação de uma identidade política comum" (SALVARO, 2010, p. 62). A definição e abrangência da categoria camponesa são explicadas em documentos do MMC:

Somos mulheres camponesas: agricultoras, arrendatárias, meeiras, ribeirinhas, posseiras, boias-frias, diaristas, parceiras, extrativistas, quebradeiras de coco, pescadoras artesanais, sem-terra, assentadas [...] Mulheres índias, negras, descendentes de europeus. Somos a soma da diversidade do nosso país. Pertencemos à classe trabalhadora, lutamos pela causa feminista e pela transformação da sociedade. (MMC BRASIL, 2013b).

Nesse sentido, a partir de uma mesma identidade política, reúnem-se mulheres trabalhadoras em lutas pela igualdade de gênero e transformação da sociedade. As ações coletivas evidenciam condições históricas e políticas que propiciaram a construção de lutas empreendidas por trabalhadoras rurais a partir de demandas por reconhecimento profissional e igualdade de gênero, assim como pela defesa da vida e garantia de diretos. Em grande medida, ao longo da trajetória dos movimentos sociais de trabalhadoras rurais, são produzidas demandas e lutas por redistribuição/reconhecimento (FRASER, 2007) nos campos socioeconômico, político, cultural e subjetivo.

A respeito do tema da violência contra as mulheres rurais, especificamente no campo dos estudos rurais, Scott, Rodrigues e Saraiva (2010) identificam uma lacuna. No entanto, segundo o/as autor/as, "nos últimos cinco anos a violência contra a mulher vem sendo reivindicada como pauta de discussão nos movimentos de mulheres trabalhadoras rurais". Tal acontecimento pode ser constatado 
pelo tema "Contra a Fome, a Pobreza e a Violência Sexista" das edições de 2000, 2003 e 2007 da Marcha das Margaridas², as quais reuniram reivindicações que realçaram "a legalização trabalhista e a benefícios previdenciários, mas evidenciaram que também havia demandas existentes para lidar com o problema, bastante silenciado, de violência." (SCOTT; RODRIGUES; SARAIVA, 2010, p. 65- 66).

Sobre a Marcha das Margaridas, Silva (2008, p. 88) ressalta sua ocorrência a cada três anos, em Brasília, envolvendo a participação de mulheres oriundas de todas as regiões brasileiras, sendo que "a denominação como Marcha das Margaridas foi uma forma de tornar pública a situação de desigualdades nas quais vivem as trabalhadoras rurais, evidenciar as diversas formas de violência enfrentadas e situação de pobreza na qual vivia a maioria das mulheres".

Em um cenário mais amplo de lutas pelo fim das violências, além da Marcha das Margaridas, é importante citar que, no ano de 2008, por ocasião da Conferência Internacional da Via Campesina em Moçambique, de acordo com Daron (2010, p. 83). o MMC e a Via Campesina ${ }^{3}$ definiram a realização de uma "Campanha mundial da Via Campesina para acabar com as violências contra as mulheres." Ainda, em um cenário mais amplo de lutas pelo fim das violências e em torno de outras demandas das mulheres, Nobre (2016, p. 649) faz referência à seguinte "aliança estratégica":

Por exemplo, a aliança estratégica entre Marcha Mundial das Mulheres e Via Campesina resultou em novas sínteses na abordagem da soberania alimentar, incorporando questões como a partilha do trabalho doméstico, o reconhecimento de saberes acumulados pelas mulheres na produção e no preparo dos alimentos, a resistência à violência contra as mulheres perpetrada por companheiros e acirrada em contextos de "açambarcamento" de terras.

Especificamente, no âmbito das ações da Secretaria de Políticas para as Mulheres (SPM) e da elaboração de políticas públicas pelo Estado brasileiro, faz-se referência "As Diretrizes e Ações Nacionais de Enfrentamento à Violência contra as Mulheres do Campo e da Floresta" (BRASIL, 2011), enquanto resultado de diálogos entre o Governo Federal e sociedade civil organizada. Conforme já observado, de igual modo, no referido documento, pontua-se a ausência de pesquisa e conhecimento sobre o fenômeno da violência contra as mulheres em tais contextos, assim como os desafios para a elaboração e efetivação de políticas públicas.

As diretrizes e ações para o enfrentamento da violência contra as mulheres do campo e da floresta devem ser compreendidas no âmbito das reivindicações do movimento de mulheres e da sociedade civil organizada, assim como das políticas de garantia de direitos das

\footnotetext{
${ }^{2}$ A Marcha das Margaridas, assim intitulada em homenagem à líder camponesa Margarida Alves, assassinada em agosto de 1983 (SILVA, 2008).

${ }^{3}$ Surgida em 1993, em Mons, Bélgica, “[...] La Vía Campesina es un movimiento internacional que reúne a millones de campesinos, agricultores pequeños y medianos, sin tierra, jóvenes y mujeres rurales, indígenas, migrantes y trabajadores agrícolas de todo el mundo." Disponível em: <https:/viacampesina.org/es/la-via-campesina-la-voz-las-campesinas-loscampesinos-del-mundo/>.Acesso em: 29 abr. 2018.
} 
mulheres, em especial do II Plano Nacional de Políticas para as Mulheres, da Política e do Pacto Nacional de Enfrentamento à Violência contra as Mulheres. (BRASIL, 2011, p.9).

No âmbito das ações para o enfrentamento da violência contra as mulheres do campo e da floresta, Scott et al. (2016, p.851), em artigo com o objetivo de "analisar as redes institucionais e de interconhecimento, acionadas, pelas mulheres rurais, para enfrentar a violência, em municípios do Sertão de Pernambuco, Brasil”, destacam especificidades que decorrem dos contextos rurais onde vivem as mulheres e obstáculos que podem ser encontrados, dentre os quais o próprio acesso às redes e aos serviços de atendimento.

No caso específico do MMC, considerando a dinamicidade e a importância sociopolítica das ações coletivas em lutas de classe, gênero, raça/etnia, entre outras, é possível levantar os seguintes questionamentos: Como situações de violência contra as mulheres começam a demandar a produção de bandeiras de luta no MMC? Quais agenciamentos históricos, políticos e subjetivos produzem a visibilidade da violência contra as mulheres em contextos de luta? Tais indagações a propósito de lutas pelo fim da violência contra as mulheres sugerem retomar questões relativas a trajetórias anteriores e posteriores à unificação de diferentes movimentos rurais autônomos de mulheres e à criação do MMC. Para tal fim, as reflexões ora propostas são feitas a partir do diálogo com estudos realizados sobre movimentos rurais autônomos de mulheres e o MMC em diferentes regiões do Brasil e da análise de publicações e discussões relacionadas ao $1^{\circ}$ Encontro Nacional do Movimento de Mulheres Camponesas, realizado no ano de 2013.

\section{MOVIMENTO DE MULHERES CAMPONESAS: TRAJETÓRIAS DE RESISTÊNCIA E DE LUTA}

Em uma breve incursão histórica, constata-se que, no Brasil, conforme ressalta Deere (2004), a década de 1980 foi marcada pela criação e organização de movimentos de mulheres rurais. Em estudo comparativo acerca de organizações de mulheres rurais no Brasil e no México, Stephen (1996, p. 57) ressalta que

no Brasil, tanto como mulheres sem-terra ou como pequenas produtoras e/ou proprietárias, as mulheres entraram na atividade política no papel de 'mulheres trabalhadoras rurais', e foram encorajadas como iguais por ativistas e dirigentes que falavam um discurso de igualdade de gênero, mas foram despertadas para um novo tipo de ação política - aquele que questionava o seu status subordinado em razão do gênero dentro da Igreja e no interior dos sindicatos de esquerda e dos movimentos sociais rurais em que participavam.

Nesse sentido, de acordo com Cappellin (2012, p. 645), “as mobilizações das trabalhadoras rurais ilustram muito bem a capacidade das mulheres de vincular reflexões sobre a vida doméstica às demandas dos movimentos populares". Esta articulação de demandas e resistências pode ser 
evidenciada desde a primeira metade da década de 1980, pelo modo como trabalhadoras rurais vêm se organizando em lutas pelo reconhecimento e pela redistribuição social, em defesa da vida e da garantia de direitos. Como destacado, no contexto brasileiro, os movimentos sociais rurais de mulheres assumiram diferentes nomeações de acordo com suas regiões de origem. Em estudo que antecedeu a unificação e a denominação MMC, Paulilo (2004, p. 242) evidencia que, "embora exista uma organização nacional conhecida como Movimento de Mulheres Trabalhadoras Rurais (MMTR) e assim ele seja conhecido também no Rio Grande do Sul”, nos estados de Santa Catarina e Paraná, eram nominados respectivamente, de Movimento de Mulheres Agricultoras (MMA) e Organização de Mulheres Rurais (OMTR).

Em um contexto amplo de lutas e resistências, verificam-se ações coletivas no sentido da construção das mulheres como sujeitos políticos em lutas pelo reconhecimento profissional como trabalhadora rural e, por consequência, a possibilidade de acesso a direitos trabalhistas e à redistribuição socioeconômica (SALVARO, 2010). Sobre as lutas por reconhecimento profissional como trabalhadora rural, cabe destacar que foram realizadas importantes companhas de informação/formação em âmbitos regionais e nacional. Como parte do processo, a Articulação de Instâncias de Mulheres Trabalhadoras Rurais - Sul (AIMTR/SUL, 1994) distribuiu a cartilha de formação e informação no 1, intitulada "Nenhuma Trabalhadora Rural Sem Documentos"; em 1997, a Articulação Nacional de Mulheres Trabalhadoras Rurais lançou uma nova cartilha - "Nenhuma Trabalhadora Rural Sem Documentos!” (ANMTR-BRASIL, 1997). Em 2004, com base nas edições anteriores, a cartilha foi publicada pelo Movimento de Mulheres Camponesas do Brasil (MMC/BRASIL, 2004).

Como nas regiões sul e sudeste do País, Butto (2006) faz referência à Campanha Nacional de Documentação, promovida pela ANMTR, e ressalta que, no nordeste, a campanha por documentos legais foi organizada pelo Movimento de Mulheres Trabalhadoras Rurais - MMTR-NE. Butto (2006, p. 90) observa que "entre os anos de 1997 e 2001 a Campanha tornou-se prioridade do Movimento, que coordenou diversas ações e mutirões de documentação em vários municípios”. A centralidade histórica da "Campanha da Documentação Nenhuma Trabalhadora Rural Sem Documento" nas lutas empreendidas pelas trabalhadoras rurais também foi referenciada por Cordeiro (2004), no estudo realizado no Sertão de Pernambuco e Sales (2007), em estudo realizado no Ceará. Conforme analisa Cordeiro (2004), no contexto estudado, a nomeação "mulher trabalhadora rural" era usada pelas mulheres para a reivindicação de direitos, bem como para negociações no espaço privado. Como em outros estudos, Sales (2007) observou que, para as mulheres, não bastava serem produtoras, era necessário o reconhecimento social como produtoras rurais. 
A “Campanha da Documentação Nenhuma Trabalhadora Rural Sem Documento”, conforme citada nos estudos referidos, pode ser considerada parte de um conjunto mais amplo de práticas mobilizadas nas lutas por reconhecimento profissional das mulheres e redistribuição socioeconômica, as quais podem ser analisadas a partir das reflexões elaboradas por Fraser (2007) acerca da necessidade de reivindicar e negar especificidades em lutas contra desigualdades de gênero, classe, geração, entre outras. Ao contrário do que argumentam alguns proponentes dos conceitos de reconhecimento e redistribuição, para Fraser (2007), tais demandas são interdependentes, de modo que articulá-las se apresenta como questão central em lutas por justiça social. A autora argumenta que “a tarefa, em parte, é elaborar um conceito amplo de justiça que consiga acomodar tanto as reivindicações defensáveis de igualdade social quanto as reivindicações defensáveis de reconhecimento da diferença" (FRASER, 2007, p. 103).

A propósito do reconhecimento da diferença na luta pela igualdade de gênero, há que se considerar o questionamento ao sujeito universal de direito. Como problematiza Swain (2005, p. 345), "se o sujeito universal é habitualmente representado pelo macho da espécie, como não reivindicar uma especificidade e a igualdade para a obtenção de um lugar ao sol?". A necessidade de utilizar certa especificidade, segundo a autora, faz-se no contexto de reinvindicações políticas que solicitam a igualdade entre homens e mulheres, por exemplo, no âmbito das relações de trabalho, em casos de tarefas iguais, remuneração salarial igual. Sendo assim, o apelo à diferença na especificação do sujeito político se constitui em estratégia de ação.

Com a unificação e a consolidação de um movimento nacional, evidencia-se um cenário envolvendo mudanças políticas importantes nas esferas da organização e participação das mulheres, das lutas, ações e enfrentamentos coletivos. Não significa dizer que ocorreu o abandono ou a substituição das demandas e reivindicações relatadas, mas aludir às condições históricas e às políticas que propiciaram a construção de uma rede coletiva em defesa da vida e da garantia de direitos (SALVARO, 2010).

Tendo em vista os questionamentos iniciais deste texto, o que seria possível dizer de certo deslocamento das lutas em torno da interface classe/gênero para a violência de gênero/violências contra as mulheres? Enquanto estratégias de resistência e produção de outras formas de existência, na direção apontada por Foucault (2013), essas lutas geram rupturas ou se articulam?

Para discorrer acerca de tais questionamentos, na sequência, são destacadas algumas das condições de possibilidades de lutas pelo fim das violências contra as mulheres. 


\section{CONSIDERAÇÕES SOBRE A EMERGÊNCIA DE LUTAS PELO FIM DAS VIOLÊNCIAS CONTRA AS MULHERES NO MMC}

Apresentar considerações sobre a emergência de lutas pelo fim das violências contra as mulheres no MMC, no contexto brasileiro, em um primeiro momento, requer nomear ações coletivas em rede. Como uma questão central, destaca-se na legislação brasileira, nos últimos anos, no âmbito da violência de gênero, dentre outras, o acontecimento que marca rupturas e transformações diz respeito à Lei $n^{0}$ 11.340, de 7 de agosto de 2006 (BRASIL, 2006) - Lei Maria da Penha (LMP), que em seu texto dispõe:

Cria mecanismos para coibir a violência doméstica e familiar contra a mulher, nos termos do $\S 8$ o do art. 226 da Constituição Federal, da Convenção para a Eliminação de Todas as Formas de Discriminação contra as Mulheres e da Convenção Interamericana para Prevenir, Punir e Erradicar a Violência contra a Mulher; dispõe sobre a criação dos Juizados de Violência Doméstica e Familiar contra a Mulher; altera o Código de Processo Penal, o Código Penal e a Lei de Execução Penal; e dá outras providências. (BRASIL, 2006).

Lago, Ramos e Bragagnolo (2010, p. 25) ressaltam que, "no Brasil, quando se fala em violência de gênero, há sempre que levar em conta um histórico de lutas que foram travadas até se chegar à promulgação de uma legislação específica". Assim sendo, a LMP, como um ordenamento jurídico específico para as mulheres, apresenta-se como resultado de mobilizações sociais, bem como resultado de um processo mais amplo e historicamente situado.

Pitanguy e Miranda (2006, p. 21), no artigo intitulado “As mulheres e os direitos humanos”, enfatizam que "o tema da violência doméstica oferece um exemplo claro da relevância da hibridação entre as esferas nacionais e internacionais". Desde 1988, "fruto da ação combinada de movimentos feministas e órgãos governamentais de defesa de suas causas, a Constituição do Brasil reconheceu o dever do Estado de prevenir e atuar diante da violência intrafamiliar." (PITANGUY; MIRANDA, 2006, p. 21). As autoras citam a Conferência Mundial de Direitos Humanos, realizada em Viena (1993), como marco no campo dos direitos humanos das mulheres e no que envolve a afirmação da violência doméstica enquanto responsabilidade do Estado, destacando o fato de que, por parte do governo brasileiro, tendo em vista a promulgação da Constituição Federal de 1988 e reconhecimento de tal dever, não havia entraves ao apoio à Declaração. De igual modo, a propósito da violência contra a mulher, as autoras se referem à importância da Convenção de Belém do Pará (Convenção Interamericana para Prevenir, Punir e Erradicar a Violência contra a Mulher), realizada em 1994 e promulgada pelo Brasil em 1996.4

\footnotetext{
${ }^{4}$ O Decreto $n^{\circ} 1.973$, de $1^{\circ}$ de agosto de 1996, promulga a Convenção Interamericana para Prevenir, Punir e Erradicar a Violência contra a Mulher, concluída em Belém do Pará, em 9 de junho de 1994. Conforme Capítulo 1, Art. 1, "Para os efeitos desta Convenção, entender-se-á por violência contra a mulher qualquer ato ou conduta baseada no gênero, que
} 
Campos (2017, p.11) registra que a LMP promove importantes mudanças jurídicas, na medida em que "[...] rompe com a lógica privatizante da violência doméstica e o tratamento como delito de menor potencial ofensivo e propõe uma abordagem integral, entendendo a complexidade da violência doméstica e familiar". As possibilidades de enfrentamento das violências contra as mulheres remetem, portanto, ao reconhecimento e a uma compreensão mais ampla de uma rede complexa de relações desiguais de poder, uma vez que, como apregoam Narvaz e Koller (2006, p. 51), “as diversas formas de discriminação e de violência contra as mulheres são manifestação de relações de poder historicamente desiguais". A visibilidade do tema da violência é intensificada, ultrapassando os limites da vida privada e, conforme Barsted (2009, p. 423), na própria elaboração da Lei $n^{\circ}$ 11.340/2006, “assume-se que a violência contra a mulher faz parte de uma complexa imbricação entre cultura, práticas, omissões e banalizações e que, para ser superada, tem que apresentar respostas que possam romper com essa cultura, gerar novas práticas, reparar as omissões e afastar para sempre a banalização da violência".

Cabe destacar que o Art. 6 assinala que "a violência doméstica e familiar contra a mulher constitui uma das formas de violação dos direitos humanos.” (BRASIL, 2006). A propósito da violência de gênero no campo da violação dos direitos, em uma perspectiva histórica, os direitos das mulheres e das meninas, em 1993, foram "reconhecidos como parte integral dos direitos humanos pela Conferência Mundial dos Direitos Humanos, da Organização das Nações Unidas (ONU)”, configurando, "pela primeira vez, expressamente concebidos como parte integrante e indivisível dos direitos humanos universais." (NARVAZ; KOLLER, 2006, p. 51).

Como descrito, no contexto brasileiro, a LMP, no Art. 6, corrobora o entendimento da violência de gênero como violação dos direitos humanos, o que contribui para potencializar as formas de efetivação da própria lei e do enfrentamento da violência. Em artigo intitulado "Oito anos da Lei Maria da Penha - entre avanços, obstáculos e desafios”, Pasinato (2015, p. 534) observa que além do fato da LMP representar um "marco político nas lutas pelos direitos das mulheres no Brasil" e possibilitar a problematização da violência contra as mulheres no âmbito das políticas públicas, “é também um importante divisor de águas na abordagem jurídica da violência baseada no gênero, uma vez que estabelece novos patamares para o enfrentamento da violência contra as mulheres no país".

Ao tratar das principais inovações trazidas pela Lei Maria da Penha, Campos e Carvalho (2011, p. 143) ressaltam o fato de a Lei ser “[...] considerada pelas Nações Unidas um exemplo de legislação efetiva para o tratamento da violência doméstica contra mulheres"; e, entre os motivos de tais considerações, observam “[...] o acolhimento no corpo da Lei dos tratados internacionais de

cause morte, dano ou sofrimento físico, sexual ou psicológico à mulher, tanto na esfera pública como na esfera privada." Disponível em: <http://legis.senado.gov.br/legislacao/ListaTextoIntegral.action?id=122009>. Acesso em: 07 jan. 2016. 
direitos humanos das mulheres, a conceituação da violência contra mulheres como uma violência de gênero e a perspectiva de tratamento integral".

Frente à contextualização apresentada, torna-se central atentar para o fato de que as lutas das mulheres brasileiras contra a violência dirigida às mulheres e a luta das mulheres do campo podem ser analisadas como processos em paralelo, considerando suas articulações em movimentos. É fundamental considerar ainda que a emergência de demandas e lutas pelo fim das violências contra as mulheres não pode ser vista como isolada da trajetória de lutas pelo reconhecimento profissional e pela igualdade de gênero em contextos de trabalho rural. $O$ enfrentamento das violências não pode ser considerado uma ação isolada do MMC, visto que se apresenta como esforço conjunto de mulheres organizadas em movimentos sociais do campo e da floresta (DARON, 2010). A propósito da organização de uma rede de enfrentamento das violências, Daron $(2010$, p.83) descreve:

[...] são as próprias mulheres organizadas na Marcha das Margaridas, no Movimento de Mulheres Camponesas, na organização das mulheres da Via Campesina, das Mulheres do Conselho Nacional de Seringueiros/as, da Marcha Mundial de Mulheres, do Movimento Articulado de Mulheres da Amazônia (MAMA), do Fórum Nacional de Enfrentamento à Violência contra as Mulheres do Campo e da Floresta, assim como grupos e organizações de mulheres do campo e da floresta, que vêm desenvolvendo lutas, campanhas e ações cotidianas de denúncia, de resistência e educativas para a superação de todas as formas de violência contra as mulheres. Deste modo, o fenômeno da violência contra as mulheres do campo e da floresta vem sendo trazido para a sociedade e para o espaço da formulação das políticas públicas pelas mulheres do campo e da floresta através de suas organizações.

No MMC, a questão da violência integra a pauta de lutas do Movimento "desde seu surgimento, na então Organização das Mulheres da Roça em 1983, perpassando o período em que se chamava de Movimento de Mulheres Trabalhadoras Rurais, através da articulação da luta pela valorização da mulher, reconhecimento de seu trabalho e na luta pelos direitos" (DARON, 2010, p. 82-83).

Pode-se ressaltar que lutas pelo fim da violência contra as mulheres se relacionam com um campo de reivindicações mais abrangente em defesa da vida e da garantia de direitos. O que sugere certo deslocamento do corpo individualizado das mulheres para se pensar a violência de gênero e seus efeitos em uma lógica mais ampla de discriminação e desigualdade entre mulheres e homens. No debate sobre a violência de gênero, Saffioti (2001) se refere ao caráter amplo do referido conceito, diferenciando e articulando com as temáticas da violência contra mulheres, violência doméstica e violência intrafamiliar. Portanto, "as relações de gênero, sendo o pano de fundo deste tipo de violência, permitem antecipar quais são os agentes da agressão e quais são as personagens vítimas" (SAFFIOTI, 2001, p.134).

Em meio a estas considerações, faz-se referência à cartilha de formação, publicada em maio de 2004, pelo Movimento de Mulheres Agricultoras de Santa Catarina (MMA/SC), intitulada “Chega 
de Violência Contra a Mulher Agricultora". O texto de introdução do material de formação destaca que "[...] precisamos desconstruir costumes culturais que oprimem e violentam os seres humanos, principalmente a nós mulheres [...] criar espaço para a mulher que existe dentro de nós, ousando construir relações de respeito, de valorização e de igualdade” (MMA/SC, 2004, p. 1). De igual modo, para a reflexão, cabe citar as bandeiras de luta do MMC, as quais, no cenário nacional, dizem da organização e do esforço conjunto de mulheres, sobretudo no que remete ao enfrentamento de modelos que produzem/naturalizam desigualdades de classe e gênero, conforme explicitado:

\begin{abstract}
A luta central do MMC é contra o modelo capitalista e patriarcal e pela construção de uma nova sociedade com igualdade de direitos. Nesse sentido, assumimos como principal bandeira de luta o Projeto de Agricultura Camponesa Ecológico, com uma prática feminista, fundamentado na defesa da vida, na mudança das relações humanas e sociais e na conquista de direitos. (MMC BRASIL, 2013c).
\end{abstract}

Além disso, amplamente se defende: “(a) Projeto Popular de Agricultura Camponesa; (b) Ampliação dos direitos sociais; (c) Projeto Popular para o Brasil; (d) Participação política da mulher na sociedade”. (MMC BRASIL, 2013c). Cada luta se desdobra em bandeiras específicas envolvendo intersecções de gênero, classe, raça/etnia, entre outras. Por exemplo, a propósito do tema da violência, no que se refere à "ampliação de direitos sociais" e à "participação política da mulher na sociedade", respectivamente, têm-se como focos a "garantia de políticas públicas de combate à violência e proteção de mulheres e crianças" e "garantia de autonomia e não mercantilização do corpo das mulheres com o fim de todas as formas de violência (sexual, física, psicológica, estrutural,...), opressão, discriminação e dominação praticada contra as mulheres e a classe trabalhadora". (MMC BRASIL, 2013c).

No conjunto das bandeiras em pauta, a noção de violência é ampliada e evidencia questões relativas à existência humana e à violação de direitos. Constata-se que as demandas expressas e que mobilizam ações de enfrentamento não se limitam à esfera considerada privada ou a situações de violência sofridas por mulheres no contexto doméstico, mas denunciam desigualdades de gênero que regulam e controlam existências individuais e coletivas nas esferas privada e pública. Nesse caso, a luta pelo "fim de todas as formas de violência", como anunciado, representa lutar pela "ampliação de direitos sociais" e pela "participação política da mulher na sociedade". Sobre a abrangência do fenômeno da violência contra a mulher, a cartilha de formação do MMC Brasil $(2009$, p. 7) traz a seguinte explanação:

Dentre as tantas opressões, a violência contra as mulheres é a manifestação mais dura e cruel da discriminação. É um fenômeno universal, multifacetado, com uma diversidade enorme de manifestações, com impactos e consequências nos mais diversos campos, seja do bem [sic] estar físico e mental das pessoas afetadas, seja na economia, na política, na saúde e sexualidade feminina. A violência é sempre uma demonstração de poder contra outra pessoa, 
grupos ou comunidades e com impactos danosos para a humanidade. Contudo ela se apresenta de forma diferenciada para homens e mulheres.

Conforme o mesmo material de formação, enquanto manifestação da discriminação, a violência contra as mulheres se configura como parte de um sistema capitalista patriarcal, responsável por diferentes formas de exploração:

A exploração da força de trabalho; exploração sobre o ser mulher com certos padrões a seguir; exploração do corpo seja para reproduzir mão de obra, seja para "serviços" sexuais ou carregar drogas e armas nas penitenciárias, por exemplo; exploração sobre a sexualidade em vista de propaganda e lucro, seja na formação de "novos" padrões de comportamentos afetivo-sexual e assim por diante. (MMC, 2009, p. 15).

Além da importância atribuída aos materiais de informação/formação sobre o tema da violência e a relação intrínseca com fatores culturais, socioeconômicos e políticos, a centralidade das demandas e enfrentamentos pode ser observada na medida em que, no ano de 2013, "cerca de três mil mulheres camponesas vindas de 23 estados, que passaram quatro dias reunidas em Brasília no $1^{\circ}$ Encontro Nacional do Movimento de Mulheres Camponesas, fizeram ecoar o tema central do evento em frente ao Congresso Nacional: 'Na sociedade que a gente quer, basta de violência contra a mulher"”. (MMC BRASIL, 2013d).

$\mathrm{O} 1^{\circ}$ Encontro Nacional do MMC trouxe a violência contra a mulher como foco central de debate e reflexão. De acordo com um trecho de sua Declaração, o “[...] encontro trouxe e aprofundou o tema e os desafios que envolvem a luta pelo fim da violência contra a mulher, entendendo que a violência é resultado do sistema capitalista, da cultura patriarcal e machista que perpassa todas as dimensões da sociedade" (MMC BRASIL, 2013e). No cenário em que emergem, diferentes formas de violência são produzidas em decorrência de práticas históricas envolvendo questões econômicas, sociais e culturais, as quais ultrapassam os limites da casa e da família.

Outro fragmento de texto da Declaração do $1^{\circ}$ Encontro também contribui para problematizar as lutas em foco, pois evidencia desafios para a superação da violência e a necessidade de concentrar esforços em quatro grandes eixos de reflexão, a saber: “a) As lutas camponesas feministas e populares; b) A produção diversificada de alimentos saudáveis; c) A Seguridade Social, universalização do salário maternidade e ampliação de 4 para 6 meses para todas as mulheres trabalhadoras; d) A importância da organização do Movimento Mulheres Camponesas". (MMC BRASIL, 2013e).

Do modo como foi apresentado na referida declaração, o tema da violência contra as mulheres demonstra intersecções com gênero, classe e geração. A propósito da relevância de tais especificidades no âmbito da temática em pauta, o estudo realizado por Pereira (2015) sobre o MMC Brasil, entre outros aspectos centrais ao debate, ressalta certa compreensão da violência que articula 
opressões de sexo e classe social, sendo que o direito a uma vida sem violência demanda lutar pelo fim das opressões patriarcais e capitalistas.

No que concerne à violência de gênero, Daron (2010, p. 15) explicita que a violência “está no cotidiano das mulheres do campo e da floresta, que sofrem a violência exercida pelos homens, particularmente no âmbito doméstico em suas formas mais agressivas e no ambiente de trabalho em suas formas discriminatórias de acesso ao poder e à renda". Nesse caso, as lutas "pelo fim da violência contra a mulher", empreendidas pelo MMC, podem ser lidas a partir de outras condições históricas de possibilidade. Mas, "o que o MMC está fazendo" para o enfrentamento da violência?

Rompemos o "silêncio", condenamos o sistema capitalista patriarcal porque estamos convencidas de que as mulheres como seres humanos são dotadas de capacidades criadoras e por isso, capazes de criar outras formas de vida em que as relações sociais e entre os gêneros sejam de igualdade de direitos e justiça. (MMC BRASIL, 2014).

Em pesquisa sobre o Movimento de Mulheres Camponesas, Táboas (2014) traz para o foco de análise o enfrentamento da violência doméstica e familiar na interface com os direitos humanos. Entre outros aspectos, a autora identifica três elementos centrais no que se refere ao enfrentamento da violência doméstica e familiar contra mulheres camponesas, a saber:

a) formação (educação) como prática política capaz de transformar relações desiguais de poderes; b) protagonismo da mulher, em um processo de desnaturalização da violência, indignação, empoderamento e ação promotora da libertação, do rompimento do ciclo da violência; e c) necessidade de promoção da autonomia econômica, vale ressaltar a observação de que a violência não decorre da dependência econômica, porém foi alertado pelas entrevistadas que é elemento presente em parte considerável dos casos e que se soma a outros fatores socioculturais agravando as situações. (TÁBOAS, 2014, p. 98).

No folder da campanha intitulada "Mulheres Camponesas na Luta Contra a Violência" (MMC BRASIL, 2014), por fatores inerentes ao próprio modo de vida e trabalho, são descritas algumas peculiaridades em relação ao fenômeno da violência contra a mulher do campo e da floresta, conforme segue:

1) as mulheres vivem numa realidade onde as moradias são distantes uma das outras, e por isso, ao sofrerem violência mesmo que gritem por socorro, não serão ouvidas;

2) a cultura machista no campo e na floresta é muito forte, o conservadorismo tradicional também, onde a mulher é tida como propriedade do seu companheiro;

3) a cultura de submissão das mulheres é ainda muito forte tornando as várias formas de violência naturalizadas pelas próprias mulheres;

4) a cultura do imoral, do feio, da roupa suja se lava em casa, do medo, são elementos fortes para manter as mulheres caladas;

5) a dependência econômica também é um empecilho para romper o silêncio e denunciar, pois é difícil para as camponesas do campo e da floresta visualizarem rumos pós denúncia. (grifos no original).

As peculiaridades descritas demonstram a complexidade da violência contra a mulher do campo e da floresta na/pela articulação das esferas privada e pública, evidenciando a norma 
heterossexual na base da própria violência. Nesse caso, as características geográficas, socioculturais, econômicas e políticas contribuem para a produção/legitimação de situações de violência silenciadas. Sobre os contextos das situações de violência, é interessante retomar algumas das questões tratadas na cartilha de formação elaborada pelo MMA/SC no ano de 2004. Seu conteúdo, organizado em três encontros de formação, entre outras questões centrais, problematiza a naturalização das violências praticadas contra as mulheres, apresenta determinada definição conceitual e faz referência a uma pesquisa realizada no ano de 2002 pelo MMA/SC no estado catarinense. No universo pesquisado, as situações de violência foram assim representadas pelas mulheres entrevistadas: "10\% das entrevistadas atribuíram como maior violência a agressão física; $12 \%$ disseram que a maior violência é a agressão moral; 28\% mencionaram a agressão política - falta de direitos; $26,18 \%$ não quiseram responder.” (MMA/SC, 2004, p. 7). De forma específica, a propósito do percentual das entrevistadas que não quiseram responder, fez-se referência ao "silêncio presente" quando se trata do tema da violência.

Convém destacar o indicativo da agressão política - falta de direitos, que vem ao encontro da reflexão de Daron (2010) acerca da "violência pela sobrecarga, exploração e não reconhecimento do trabalho". Segundo a autora, a tripla jornada cotidiana de trabalho vivenciada por mulheres do campo e da floresta, imposta pelos modelos patriarcal e de desenvolvimento capitalista, "[...] aliada com a exploração e a invisibilidade do trabalho, faz com que a mulher seja violentada num dos seus direitos fundamentais: o trabalho e a dignidade.” (DARON, 2010, p. 35).

Com base no que argumenta Daron sobre a violência vivenciada por mulheres do campo e da floresta nas esferas política e econômica, pode-se dizer que existe determinado modelo binário masculino/feminino e hegemônico de gênero, por meio do qual são produzidas/naturalizadas posições sociais hierarquizadas e subordinadas entre os sexos. A hegemônica divisão sexual do trabalho em torno de atividades consideradas produtivas e reprodutivas, por exemplo, apoia-se em um modelo binário de gênero, mediante o qual se atribui às mulheres posições sociais desiguais em relação aos homens, as quais envolvem jornadas de trabalho múltiplas e extensas, trabalhos precários e desvalorizados socialmente, desigualdade salarial, entre outras. Com base no explicitado, compreende-se que a banalização da violência cede lugar à problematização de gênero, possibilitando condições de enfrentamento ${ }^{5}$.

\footnotetext{
${ }^{5} \mathrm{O}$ cenário de violências contra as mulheres, bem como a urgente necessidade de redes de enfrentamento podem ser evidenciados, por exemplo, quando são apresentados os números relativos aos assassinatos de mulheres no Brasil. De acordo com o Mapa da Violência 2015 - Homicídio de Mulheres no Brasil (WAISELFISZ, 2015, p. 11), com base nos registros do Sistema de Informação de Mortalidade (SIM), no período de 1980-2013, 106.093 mulheres foram assassinadas; "a taxa, que em 1980 era de 2,3 vítimas por 100 mil, passa para 4,8 em 2013, um aumento de 111,1\%". Disponível em: <http://www.mapadaviolencia.org.br/pdf2015/MapaViolencia_2015_mulheres.pdf >. Acesso em: 07 jan. 2016.
} 


\section{PROBLEMATIZANDO O BINÁRIO DE GÊNERO EM LUTAS PELO FIM DAS VIOLÊNCIAS CONTRA AS MULHERES}

Feix (2011, p. 202) refere-se à violência contra as mulheres "como dispositivo eficaz e disciplinador das mulheres no cumprimento do papel de subordinação que lhes é atribuído; sendo, portanto, um componente fundamental no sistema de dominação". A autora reconhece se tratar de uma "violência política" para assegurar relações desiguais pela superioridade e dominação masculina em diferentes culturas.

No debate sobre redistribuição e reconhecimento do gênero e suas dimensões políticoeconômicas, Fraser (2001) destaca o seu caráter fundador na estrutura da divisão do trabalho reprodutivo e produtivo, não assalariado e assalariado, respectivamente, atribuído a mulheres e a homens, de modo a problematizar, também, a diferenciação cultural-valorativa da estrutura em questão. Logo, conforme conclui a autora, "eliminar a exploração, marginalização e privação específica do gênero requer a abolição da divisão de gênero do trabalho" e se apresenta como uma parte da história, na medida em que na/pela diferenciação cultural-valorativa, "uma característica principal da injustiça de gênero é o androcentrismo: a construção autoritária de normas que privilegiam características associadas com a masculinidade.” (FRASER, 2001, p. 260).

Com base na reflexão apresentada até agora a respeito da violência contra a mulher como violência de gênero, coloca-se em questão o modelo binário masculino/feminino, uma vez que evidencia a produção/naturalização de desigualdades entre mulheres e homens em diferentes esferas da vida. A propósito, cabe mencionar, como já alertou Butler (2003), a problematização da noção binária masculino/feminino do gênero, bem como dos efeitos de uma matriz heterossexual de inteligibilidade, na construção de uma política feminista. No caso da violência de gênero, convém refletir sobre as normas de gênero na/pela materialidade dos corpos. Como problematiza Butler (2003, p. 27), “em que medida pode o corpo vir a existir na(s) marca(s) do gênero e por meio delas?".

A respeito de concepções que presumem "uma pessoa substantiva" e determinada "posição feminista humanista" que "compreenderia o gênero como um atributo da pessoa", Butler (2003, p. 29), por um lado, analisa a noção de um "núcleo" de gênero preestabelecido e sua pretensa universalidade; por outro, ressalta o deslocamento da concepção universal, impulsionado por "posições históricas ou antropológicas" que tematizam sobre o aspecto relacional e contextual do gênero, de modo a fundamentar que "o gênero não denota um ser substantivo, mas um ponto relativo de convergência entre conjuntos específicos de relações cultural e historicamente convergentes". Quanto ao aspecto relacional e contextual do gênero, Butler recomenda ver o clássico artigo de Scott (1988), intitulado "Gender: A Useful Category of Historical Analysis", traduzido para o português e 
publicado no Brasil em 1990, com o título "Gênero: uma categoria útil de análise histórica, pela Revista Educação e realidade."

Em ambos os posicionamentos e teorizações de gênero, quer como atributo da pessoa ou contextual/relacional, pode-se perguntar como os corpos são produzidos e normatizados por um discurso cultural hegemônico no interior da estrutura binária masculino/feminino, por meio da qual se configuram práticas reguladoras de gênero. Butler (2003) sugere pensar a identidade de gênero como efeito de uma prática discursiva e reguladora, de modo a problematizar a construção fictícia de homens e mulheres como substâncias permanentes. Para Michel Foucault, citado por Butler (2003, p. 41), "a gramática substantiva do sexo impõe uma relação binária artificial entre os sexos, bem como uma coerência interna artificial em cada termo desse sistema binário". Como efeito discursivo, a lógica binária regula a sexualidade e restringe possibilidades de subversão das "hegemonias heterossexual, reprodutiva e médico-jurídica.” (BUTLER, 2003, p. 41).

A autora argumenta que o gênero não é um substantivo, mas performático, na medida em que "seu efeito substantivo é performaticamente produzido e imposto pelas práticas reguladoras da coerência de gênero", revelando-se como um feito de um sujeito não "preexistente à obra." (BUTLER, 2003, p. 48). A partir do que se estabelece, a compreensão e a teorização do gênero são orientadas por condições de possibilidade que permitem, entre outras questões, estranhar e desconstruir a ordem compulsória do sexo/gênero/desejo. Por conseguinte, pela desconstrução da aparência substantiva do gênero e por seu caráter performativo, Butler (2003, p. 59) demonstra que “a univocidade do sexo, a coerência interna do gênero e a estrutura binária para o sexo e o gênero são sempre consideradas como ficções reguladoras que consolidam e naturalizam regimes de poder convergentes de opressão masculina e heterossexista".

Para além do binário masculino/feminino e da heterossexualidade compulsória, Butler oferece subsídios teóricos e conceituais que possibilitam refletir sobre a violência do gênero. Como já se anunciou em referência à violência contra a mulher no âmbito da violência de gênero, coloca-se em questão o modelo binário masculino/feminino do gênero. Parece coerente, então, sugerir que as diferentes formas de violência contra as mulheres revelam normas que produzem hierarquias, subordinam e desigualam o corpo feminino. Em um sentido mais amplo, se a violência contra a mulher é uma violação de direitos humanos, conforme anteriormente mencionado, o modelo binário em questão nega às mulheres o reconhecimento como sujeitos de direito.

Ao tratar do reconhecimento social-político dos sujeitos, Butler (2012) problematiza discursos restritivos de gênero que possibilitam ou não tal reconhecimento. Na reflexão desta autora, dois significados para a concepção de "sujeito" são apresentados: aquele que é reconhecido como indivíduo-pessoa e aquele que é/está sujeito aos discursos normativos. Sendo assim, Butler observa 
que as normas de gênero fundamentam as regras e as leis e têm consequências de longo alcance, envolvendo a esfera de direitos humanos e a participação política.

Tendo em conta que o gênero produz/naturaliza as noções de masculino e feminino, como já demonstrado, de acordo com Butler (2012), o próprio aparato pode funcionar para desnaturalizar e descontruir. No dizer da autora, implica desfazer o gênero, romper com o binário e parar de criar normas restritivas que nominam a masculinidade/feminilidade. Em vista disso, as lutas pelo fim da violência contra as mulheres e da produção de outras formas de existência requerem a desconstrução de uma matriz binária e hegemônica do gênero.

\section{CONSIDERAÇÕES FINAIS}

O presente artigo apresenta reflexões iniciais sobre a emergência de lutas pelo fim da violência contra as mulheres, empreendidas pelo Movimento de Mulheres Camponesas do Brasil (MMC BRASIL). A partir do diálogo com estudos realizados sobre movimentos rurais autônomos de mulheres e o MMC em diferentes regiões do Brasil, da análise de publicações e de discussões relacionadas ao $1^{\circ}$ Encontro Nacional do Movimento de Mulheres Camponesas, realizado no ano de 2013, foram tecidas considerações que visibilizam as violências de gênero e contra as mulheres na interface com reivindicações por reconhecimento profissional, defesa da vida, garantia de diretos e igualdade de gênero, entre outras demandas.

As análises bibliográfica e documental possibilitaram argumentar que ações de enfrentamento à violência contra as mulheres denunciam desigualdades de gênero que regulam/controlam existências individuais e coletivas nas esferas privada/pública. Buscou-se, então, discorrer sobre o fato de que lutas pelo fim da violência contra as mulheres se relacionam com um campo de reivindicações mais abrangente em defesa da vida e da garantia de direitos, sugerindo o deslocamento do corpo individualizado das mulheres para se pensar sobre uma lógica mais ampla de discriminação e desigualdade, fundamentada na produção/naturalização do binário masculino/feminino do gênero.

Por ora, para concluir, na luta pela garantia de direitos humanos das mulheres, é central não esquecer que a positivação de direitos no ordenamento jurídico não é suficiente para garantir a igualdade substantiva e o fim da violação de direitos. As lutas concretas pelo fim da violência contra as mulheres denunciam a distância entre o sujeito abstrato da representação e as experiências singulares das mulheres. 


\section{REFERÊNCIAS}

ARTICULAÇÃO NACIONAL DE MULHERES TRABALHADORAS RURAIS - ANMTR Brasil. (1997). Nenhuma Trabalhadora Rural sem Documentos. Cartilha. Passo Fundo/RS: Impressão Gráfica e Editora Pe. Berthier, 1997.

\section{ARTICULAÇÃO DE INSTÂNCIAS DE MULHERES TRABALHADORAS RURAIS/SUL - AIMTR/Sul. Nenhuma Trabalhadora Rural sem Documentos! Cartilha. Passo Fundo/RS: Gráfica Battistel, 1994.}

BARSTED, Leila Linhares. A Convenção de Belém do Pará, a Lei Maria da Penha e o Atendimento a Homens Agressores. In: TORQUIST, Carmen Susana et al. (Org.). Leituras de resistência: corpo, violência e poder. Vol. II. Florianópolis: Ed. Mulheres, 2009, p. 419-427.

BRASIL. Constituição (1988). Constituição da República Federativa do Brasil. Brasília, DF: Senado Federal: Centro Gráfico, 1988. 292 p.

BRASIL. Decreto n⿳ 1.973, de $1^{\circ}$ de agosto de 1996. Promulga a Convenção Interamericana para Prevenir, Punir e Erradicar a Violência contra a Mulher, concluída em Belém do Pará, em 9 de junho de 1994. Disponível em:

$<$ http://legis.senado.gov.br/legislacao/ListaTextoIntegral.action?id=122009>. Acesso em: 07 jan. 2016.

BRASIL. Secretaria Nacional de Enfrentamento à Violência contra as Mulheres. Secretaria de Políticas para as Mulheres. Mulheres do Campo e da Floresta: Diretrizes e Ações Nacionais. Brasília, 2011. Disponível em: <http://www.spm.gov.br/sobre/publicacoes/publicacoes/2011/campoe-floresta>. Acesso em: 27 jul.2016.

BRASIL. Lei $\mathbf{n}^{\mathbf{0}} \mathbf{1 1 . 3 4 0}$, de 7 de agosto de 2006. Cria mecanismos para coibir a violência doméstica e familiar contra a mulher, nos termos do $\S 80$ do art. 226 da Constituição Federal, da Convenção sobre a Eliminação... Brasília, DF, 8 ago. 2006. Disponível em:

$<$ http://www.planalto.gov.br/ccivil_03/_ato2004-2006/2006/lei/111340.htm>. Acesso em: 21 jul.2016.

BUTLER, Judith. Deshacer el Género. Barcelona: Paidós, 2012.

BUTLER, Judith. Problemas de gênero: feminismo e subversão da identidade. Rio de Janeiro:

Civilização Brasileira, 2003. 
BUTTO, Andréa. Políticas para as mulheres rurais: um compromisso de todos os dias. In: BRASIL. Ministério do Desenvolvimento Agrário. Gênero, agricultura familiar e reforma agrária no Mercosul. Brasília: Ministério do Desenvolvimento Agrário, 2006, p. 87-116. Disponível em: $<$ http://www.mda.gov.br/sitemda/sites/sitemda/files/anexos/livro_genero_agricultura_familiar_e_R A_no_mercosul_0.pdf $>$. Acesso em: 20 jan. 2016.

CAMPOS, Carmen Hein de. Lei Maria da Penha: necessidade de um novo giro paradigmático. Rev. bras. segur. Pública, São Paulo v. 11, n. 1, 10-22, Fev/Mar 2017. Disponível em:

$<$ http://revista.forumseguranca.org.br/index.php/rbsp/article/view/778>. Acesso em: 05 out.2017.

CAMPOS, Carmen Hein de; CARVALHO, Salo de. Tensões atuais entre a criminologia feminista e a criminologia crítica: a experiência brasileira. In: CAMPOS, Carmen Hein de. (Org.). Lei Maria da Penha comentada em uma perspectiva jurídico-feminista. Rio de Janeiro: Editora Lumen Juris, 2011, p. 143-169. Disponível em: $<$ http://www.compromissoeatitude.org.br/wpcontent/uploads/2014/02/LMP_editado_final.pdf >. 13 out.2017.

CAPPELLIN, Paola. Os movimentos de trabalhadoras e a sociedade brasileira. In: DEL PRIORI, Mary. (Org.). História das mulheres no Brasil. 10. ed. São Paulo: Contexto, 2012, p. 640-668.

CORDEIRO, Rosineide de Lourdes Meira. Além das secas e das chuvas: os usos da nomeação mulher trabalhadora rural no Sertão de Pernambuco. 2004. Tese (Doutorado em Psicologia Social) Pontifícia Universidade Católica de São Paulo, São Paulo, 2004.

DARON, Wanderléia Laodete Pulga. Um Grito Lilás: Cartografia da violência às mulheres do campo e da floresta. Brasília: Secretaria de Políticas para as Mulheres, 2010 (Livro Eletrônico). Disponível em: <http:/www.spm.gov.br/arquivos-diversos/sev/coordenacao-geral-de-acoespreventivas-e-garantia-de-direitos/enfrentamento-a-violencia-contra-as-mulheres-do-campo-e-dafloresta/documentos/um\%20grito\%20lilas.pdf>. Acesso em: 07 jan. 2016.

DEERE, Carmen Diana. Os direitos da mulher a terra e os movimentos sociais rurais na reforma agrária. Revista Estudos Feministas, Florianópolis, v. 12, n. 1, p. 175-204, jan./abr. 2004.

FEIX, Virgínia. Das formas de violência contra a mulher - artigo $7^{\circ}$. In: CAMPOS, Carmen Hein de. (Org.). Lei Maria da Penha comentada em uma perspectiva jurídico-feminista. Rio de Janeiro: Editora Lumen Juris, 2011, p. 201-213.

FOUCAULT, Michel. O sujeito e o poder. In: DREYFUS, H.; RABINOW, P. Michel Foucault: uma trajetória filosófica. Para além do estruturalismo e da hermenêutica. 2. ed. rev. Rio de Janeiro: Forense Universitária, 2013, p. 273-295.

FRASER, Nancy. Da redistribuição ao reconhecimento? Dilemas da justiça na era pós-socialista. In: SOUZA, Jessé (Org.). Democracia hoje: novos desafios para a teoria democrática contemporânea. Brasília: Ed. UNB, 2001, p. 245-282. 
FRASER, Nancy. Reconhecimento sem ética? Lua Nova: Revista de Cultura e Política, São Paulo, 70, p. 101-138, 2007. Disponível em: $<$ http://www.scielo.br/pdf/ln/n70/a06n70.pdf $>$. Acesso em: 29 set. 2017.

GOHN, Maria da Glória. Movimentos sociais na contemporaneidade. Rev. Bras. Educ., Rio de Janeiro, v. 16, n. 47, ago. 2011. Disponível em $<$ http:/Www.scielo.br/scielo.php?script=sci_arttext\&pid=S1413-

24782011000200005\&lng=pt\&nrm=iso >. Acesso em: 15 abr. 2013.

LAGO, Mara Coelho de Souza; RAMOS, Maria Eduarda; BRAGAGNOLO, Regina Ingrid. Enfrentamento da violência doméstica e familiar na legislação brasileira: Lei Maria da Penha. In: TONELI, Maria Juracy Filgueiras et al. (Orgs). Atendimento a homens autores de violência contra as mulheres: experiências latino americanas. Florianópolis: UFSC/CFH/NUPPE, 2010. p. $25-47$.

LA VÍA CAMPESINA. Movimiento Campesino Internacional. Disponível em: $<$ https://viacampesina.org/es/la-via-campesina-la-voz-las-campesinas-los-campesinos-delmundo/>.Acesso em: 29 abr. 2018.

MOVIMENTO DE MULHERES AGRICULTORAS DE SANTA CATARINA (MMA/SC). Chega de Violência Contra a Mulher Agricultora. Cartilha. Chapecó: MMA/SC, maio de 2004.

\section{MOVIMENTO DE MULHERES CAMPONESAS DO BRASIL (MMC BRASIL). Nenhuma} trabalhadora rural sem documentos. 5. ed. Cartilha. Passo Fundo/RS: Impressão Gráfica Battistel, 2004. Disponível em:

$<$ http://www.mmcbrasil.com.br/materiais/publicacoes/cartilha_documentacao.pdf $>$. Acesso em: 02 mar. 2013.

MOVIMENTO DE MULHERES CAMPONESAS DO BRASIL (MMC BRASIL). Mulheres Camponesas: caminhando rumo à superação da violência. Cartilha. MMC Brasil, 2009.

MOVIMENTO DE MULHERES CAMPONESAS DO BRASIL (MMC BRASIL). Organização. Disponível em: <http://www.mmcbrasil.com.br/site/node/46>. Acesso em: 12 abr. 2013a.

. Quem somos. Disponível em: <http://www.mmcbrasil.com.br/site/node/43>. Acesso em: 28 out. 2013b. $\overline{2013 \mathrm{c} .}$

. Lutas. Disponível em: <http://www.mmcbrasil.com.br/site/node/47>. Acesso em: 24 out.

. Camponesas fazem ato pelo fim da violência contra a mulher em frente ao Congresso Nacional, em Brasília, no encerramento do I Encontro Nacional do MMC. Disponível em: $<$ http://www.mmcbrasil.com.br/site/node/71>. Acesso em: 21 fev. $2013 \mathrm{~d}$. 
MOVIMENTO DE MULHERES CAMPONESAS DO BRASIL (MMC BRASIL). Declaração do I Encontro Nacional do Movimento de Mulheres Camponesas. Disponível em:

$<$ http://www.mmcbrasil.com.br/site/node/69>. Acesso em: 28 fev. 2013e.

. "Mulheres Camponesas na Luta Contra a Violência”. Folder. Passo Fundo/RS:

MMCBRASIL, 2014. Disponível em:

$<$ http://www.mmcbrasil.com.br/site/materiais/download/folder-violencia-contra-mulher-2014.pdf $>$. Acesso em: 07 jan. 2016.

NARVAZ, Martha Giudice; KOLLER, Sílvia Helena. Famílias e patriarcado: da prescrição normativa à subversão criativa. Psicol. Soc., Porto Alegre, v. 18, n. 1, p. 49-

55, abr. 2006. Disponível em: <http://www.scielo.br/scielo.php?script=sci_arttext\&pid=S0102$71822006000100007 \& \operatorname{lng}=$ pt\&nrm=iso $>$. Acesso em: 05 abr. 2018.

NOBRE, Miriam. Igualdade para todas: estratégias para políticas públicas e ações do movimento.

Rev. Estud. Fem., Florianópolis, v. 24, n. 2, p. 645-652, ago. 2016. Disponível em:

$<$ http://www.scielo.br/scielo.php?script=sci_arttext\&pid=S0104-

026X2016000200645\&lng=pt\&nrm=iso >. Acesso em: 23 mai. 2017.

PASINATO, Wânia. Oito anos de Lei Maria da Penha: Entre avanços, obstáculos e desafios. Rev. Estud. Fem., Florianópolis, v. 23, n. 2, p. 533-545, ago. 2015.

PAULILO, Maria Ignez Silveira. Trabalho familiar: uma categoria esquecida de análise. Revista Estudos Feministas, Florianópolis, v. 12, n. 1, p. 229-252, jan./abr. 2004.

PEREIRA, Diana Melo. Sem porta-voz na rua, sem dono em casa: as lutas do Movimento de Mulheres Camponesas (MMC Brasil) pelo direito a uma vida sem violência. 2015. $157 \mathrm{f}$. Dissertação (Mestrado em Direito) - Universidade de Brasília, Brasília, 2015. Disponível em: $<$ http://repositorio.unb.br/bitstream/10482/18885/1/2015_DianaMeloPereira.pdf >.Acesso em: 06 mar.2017.

PITANGUY, Jacqueline; MIRANDA, Dayse. As mulheres e os direitos humanos. In: O progresso das mulheres no Brasil. Brasília: UNIFEM/Ford Foudation/CEPIA, 2006, p. 14-31. Disponível em:

$<$ http://www.mpsp.mp.br/portal/page/portal/Cartilhas/Progresso\%20das\%20Mulheres $\% 20 \mathrm{no} \% 20 \mathrm{Br}$ asil.pdf>. Acesso em: 16 fev. 2018.

SAFFIOTI, Heleieth Iara Bongiovani. Contribuições feministas para o estudo da violência de gênero. Cad. Pagu, Campinas, n. 16, p. 115-136, 2001. Disponível em:

$<$ http://www.scielo.br/scielo.php?script=sci_arttext\&pid=S0104-

$83332001000100007 \& \operatorname{lng}=$ pt\&nrm=iso>. Acesso em: 19 fev. 2018. 
SALES, Celecina de Maria Veras. Mulheres Rurais: tecendo novas relações e reconhecendo direitos. Revista de Estudos Feministas, v. 15, n. 2, p. 437-443, 2007.

SALVARO, Giovana Ilka Jacinto. Entre a igualdade e a diferença: mulheres camponesas em lutas de gênero. 2010. Tese (Doutorado Interdisciplinar em Ciências Humanas) - Universidade Federal de Santa Catarina, Florianópolis, 2010.

SCHERER-WARREN, Ilse. Redes de Movimentos Sociais. 2. ed. São Paulo: Edições Loyola, 1996.

SCOTT, Joan. Gênero: uma categoria útil de análise histórica. Educação e realidade, Porto Alegre, v.16, n. 2, p. 5-22, 1990.

. Gender: A Useful Category of Historical Analysis. In: Gender and the Politics of History. New York: Columbia University Press, 1988. p.28-52.

SCOTT, Parry, et al. Redes de enfrentamento da violência contra mulheres no Sertão de Pernambuco. Rev. Estud. Fem., Florianópolis, v. 24, n. 3, p. 851-870, dez. 2016. Disponível em $<$ http://www.scielo.br/scielo.php?script $=$ sci_arttext\&pid=S0104-

026X2016000300851\&lng=pt\&nrm=iso>. Acesso em: 15 set. 2017.

SCOTT, Parry; RODRIGUES, Ana Cláudia; SARAIVA, Jeíza das Chagas. Onde mal se ouvem os gritos de socorro: notas sobre a violência contra a mulher em contextos rurais. In: SCOTT, Parry; CORDEIRO, Rosineide; MENEZES, Marilda. (Orgs.). Gênero e geração em contextos rurais. Florianópolis: Ed. Mulheres, 2010, p. 63-93.

SILVA, Berenice Gomes da. A Marcha das Margaridas: resistências e permanências. 2008. 172 f. Dissertação (Mestrado) - Universidade de Brasília, Brasília, 2008. Disponível em: $<$ http://repositorio.unb.br/handle/10482/949>. Acesso em: 21 jan. 2016.

STEPHEN, Lynn. "Relações de gênero: um estudo comparativo sobre organizações de mulheres rurais no México e no Brasil". In: NAVARRO, Zander. (Org.) Política, protesto e cidadania no campo: as lutas dos colonos e trabalhadores rurais no Rio Grande do Sul. Porto Alegre: Editora da Universidade/UFRGS, 1996, p. 29-61.

SWAIN, Tania Navarro. Mulheres, sujeitos políticos: que diferença é esta? In: SWAIN, Tania Navarro; MUNIZ, Diva do Couto Gontijo. (Orgs.). Mulheres em ação: práticas discursivas, práticas políticas. Florianópolis: Ed. Mulheres; Belo Horizonte: PUC Minas, 2005, p. 337-354. 
TÁBOAS, Ísis Dantas Menezes Zornoff. Viver sem violência doméstica e familiar: a práxis feminista do Movimento de Mulheres Camponesas. 2014. 165 f. Dissertação (Mestrado) Universidade de Brasília, Brasília, 2014. Disponível em:

$<$ http://repositorio.unb.br/bitstream/10482/18219/1/2014_IsisDantasMenezesZornoffTaboas.pdf $>$. Acesso em: 10 out. 2015.

WAISELFISZ, Julio Jacobo. Mapa da Violência 2015: Homicídio de Mulheres no Brasil. Brasília, 2015. Disponível em:

$<$ http://www.mapadaviolencia.org.br/pdf2015/MapaViolencia_2015_mulheres.pdf $>$. Acesso em: 07 jan. 2016. 